\title{
Morphological Evolution of Poly(tetrafluoroethylene) using Focused Ion Beam Irradiation
}

\author{
Richard L. Schalek \\ Center for Nanoscale Systems, Harvard University, Cambridge, MA 01880
}

Using the focused ion beam (FIB) system for the study of surface morphology evolution continues to be an important topic in engineering and surface physics [1]. Ion beam erosion of solid surfaces occurs as a consequence of material removal via sputtering, while redeposition of sputtered material and surface diffusion assist in the surface morphological evolution. These competitive effects tend to either smooth the surface topography or create cones, dots and ripples. FIB-induced morphological surface evolution has been studied in all material classes with the most thoroughly studied being the metals and semiconductors, while little work has been performed on ceramics and polymers. This work is an attempt to contribute to the understanding of the ion beam erosion of polytetrafluoroethylene (PTFE) in an effort to provide predictive capabilities for producing desired surface contouring.

Polytetrafluoroethylene (PTFE) is a semicrystalline polymer that finds widespread industrial use due to its high thermal chemical stability, dielectric properties, low surface energy and low coefficient of friction. In general, PTFE is classified as a polymer that undergoes main chain scission by ionizing irradiation that results in lower molecular weights [2]. The molecular structure, thermal sensitivity, and chemical reactivity of polymers makes ion beam erosion of polymers a more complex process than encountered in metals and semiconductors. In particular, the ion energy deposition kinetically and thermochemically transforms the macromolecular structure, while fundamentally altering the material properties of the polymer.

Experimentally, PTFE was irradiated with $3 \mathrm{nA}, 30 \mathrm{kV} \mathrm{Ga}+$ ions for up to 30 minutes using an FEI Dual Beam 235 focused ion beam system. The sample was FIBed with the ion beam at incident angles of $90^{\circ}$ (ion beam normal to the surface), $30^{\circ}$ and $10^{\circ}$. After irradiation, the specimens were sputter coated with a thin layer of $\mathrm{Pt} / \mathrm{Pd}$ to prevent charging while imaging in the scanning electron microscope.

Figure 1 shows the SEM images of the ion-eroded regions for $10^{\circ}, 30^{\circ}$, and $90^{\circ}$. A rich variety of surface features are observed. As a general observation, surface ripples are seen in the samples inclined at $10^{\circ}$, while the $30^{\circ}$ and $90^{\circ}$ specimens show the appearance of cones and spikes. A higher magnification examination of the $30^{\circ}$ irradiations, shown in Figure 2, shows that at low dose patterned rows parallel to the ion beam scan direction develop (2a) in conjunction with small cone structures (2b). As shown in Figure 2c, higher doses cause the patterned rows and small cones to disappear, giving way to a population of cones projecting from a smooth floor. In contrast to these structures, lowering the incident angle to $10^{\circ}$, results in a rippled surface. The SEM images in Figure 3 show that the ripples are parallel to the ion beam direction, with the ripple width starting small and increasing in width as the beam penetrates the specimen. Continued studies to correlate the ion beam dose with ion beam parameters and specimen geometry are currently underway and will also be presented. 

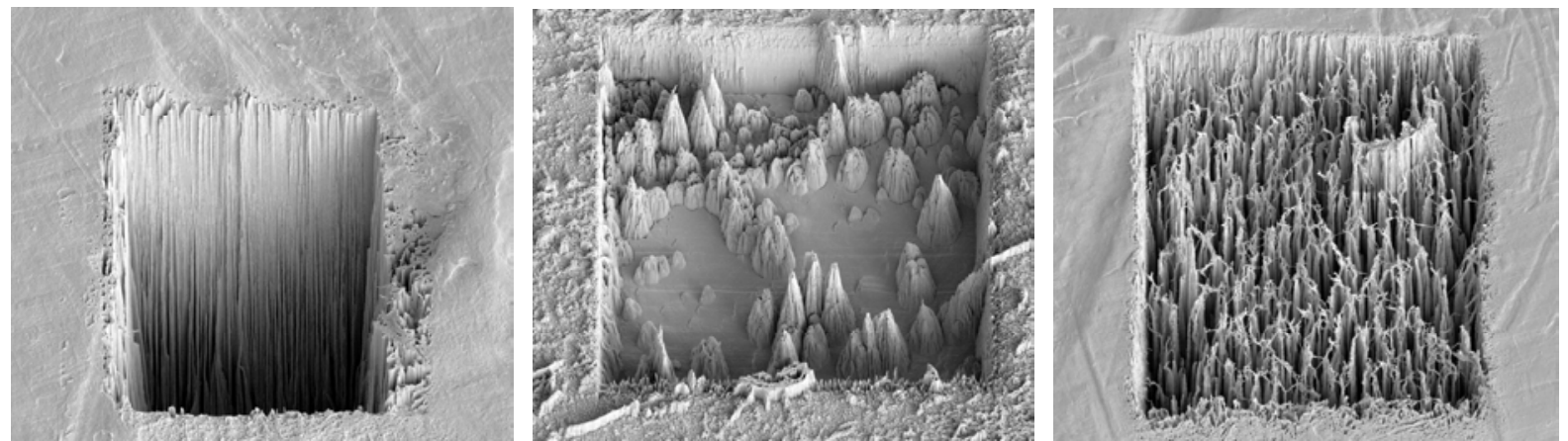

Figure 1: SEM images of PTFE irradiated with $3 \mathrm{nA}, 30 \mathrm{kV} \mathrm{Ga}^{+}$ions at an incident angle of (a) $10^{\circ}$, (b) $30^{\circ}$ and (c) $90^{\circ}$.
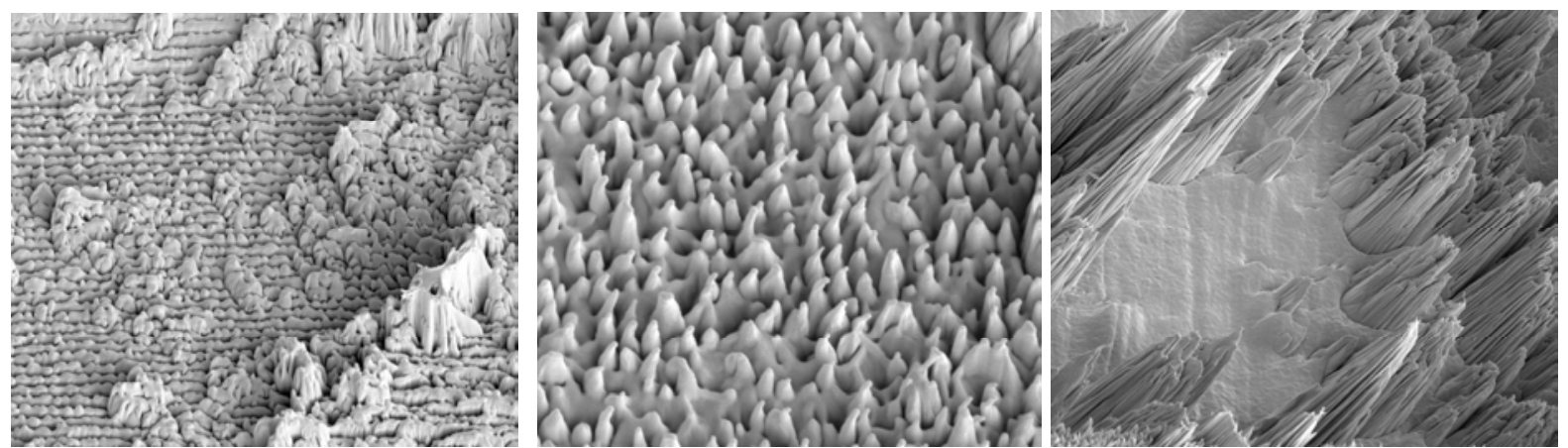

Figure 2: High magnification SEM images showing the surface morphological developments of PTFE irradiated $3 \mathrm{nA}, 30 \mathrm{keV} \mathrm{Ga}^{+}$ions at a tilt of $30^{\circ}$.
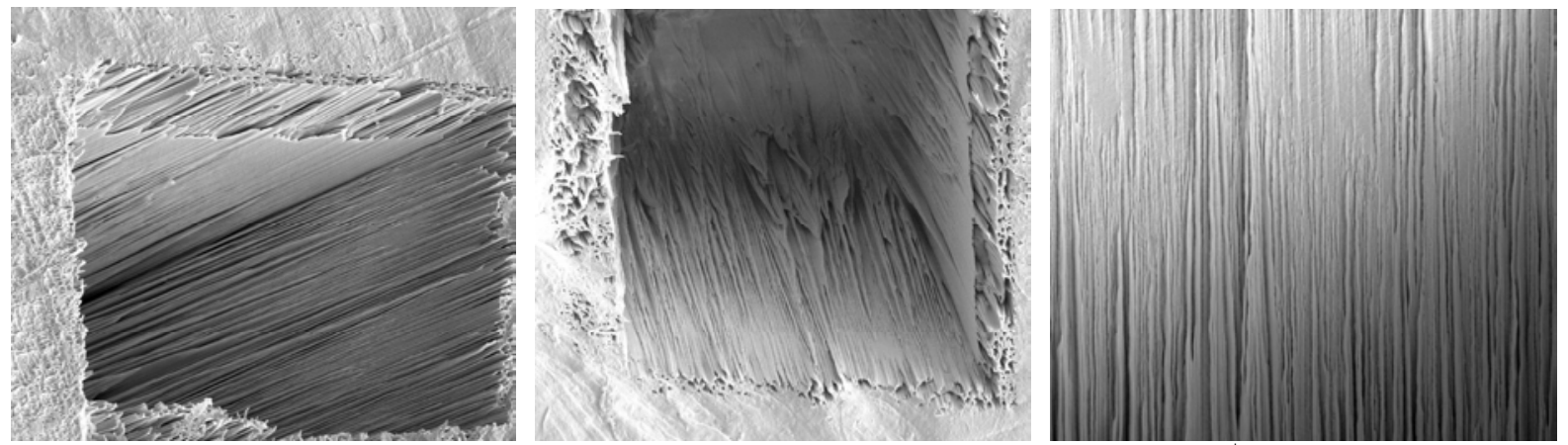

Figure 3: A closer examination of PTFE irradiated with $3 \mathrm{nA}, 30 \mathrm{keV} \mathrm{Ga}{ }^{+}$ions with an incident angle of $10^{\circ}$.

References

[1] G. Carter, J. Phys. D. Appl. Phys., 34 (2001) R1-R22.

[2] M. Dole, Ed. The Radiation Chemistry of Macromolecules, Vol. 2, Academic Press, New York, 1973. 